\title{
ARTICULADAS COM ESTRUTURA REPRODUTIVA PRESERVADA NO GONDWANA SUL-BRASILEIRO (FORMACุĀO RIO BONITO - ARTINSKIANO/KUNGURIANO)
}

Ademar Alfonso Mombach (CNPq - Bolsista) Margot Guerra-Sommer (IG/UFRGS)

Ao se iniciarem no Brasil, durante o Século XVIII, os estudos referentes as paleofloras associadas a jazidas carboniferas, são efetuadas as primeiras referências à presença de Equisetopsida relacionadas à Asterophyllites por HARTT, 1870 (in LIAIS, 1872 e ARBER, 1905) ,

Para o Rio Grande do Sul a primeira citação de articuladas é efetuada por LUNDQUIST (1919), vinculada por suas características a Schizoneura gondwanensis Feistmantel (1880). BARBOSA (1958) cita Phyllotheca sp. como elemento presente no Gondwana do Rio Grande do Sul, não sendo citada a fonte de informação em que se baseou o registro. TOWNROW (1955), de acordo com referências efetuadas por HIRMER (1927), refere a presença de Phyllotheca australis Brongniart (1828) em sedimentos carbonifero-permianos do Brasil.

A estruturação de um núcleo de paleobotânica no Instituto de Geociências da Universidade Federal do Rio Grande do Sul, na dēcada de 70, levou a realização de estudos sistemáticos, paleoecolōgi cos e fitoestratigráficos nas diferentes unidades litoestratigráfi cas do Gondwana Sul-rio-grandense, sendo elaborados mais de cinqulenta (50) trabalhos inéditos, até o presente.

A partir de estudos fitopaleoecológicos efetuados por BURJACK et. al. (1983) em estratos da Formação Rio Bonito, são efetuados por CAZZULO-KLEPZIG \& GUERRA-SOMMER (1983) estudos em fragmentos de articuladas que levam a uma tentativa de reconstituição de Phyllotheca indica Bunbury (1861) a partir de impressões produzidas por "preservação autigênica" de rizomas e partes aéreas estéreis. Este gênero (Est. 1, fig. 2) relacionado a articuladas herbảceas a arbustivas, tem como característica diagnóstica importante a presença de folhas fusionadas basalmente em uma bainha cilindrica ou cônica. As partes livres das folhas lineares, podem apresentar comprimento diferenciado, em diferentes ramos. As suturas entre as fo- 
lhas são marcadas por um sulco (Est. 1, fig. 1).

Segundo MEYEN $(1967,1987)$, Phyllotheca constitue-se em um "gênero satélite" em relação a Equisetopsida, pois fragmentos vege tativos relacionáveiss a Phyllotheca são encontrados vinculados diretamente a diferentes estruturas reprodutivas, em províncias paleofloristicas distintas, relacionando-se à Tchernoviaceae em Anga ra e à Gondwanostachyaceae no Gondwana.

MENEGAT et. al. 1989 (In GUERRA-SOMMER, 1989) registra para pelito associado a camada de carvão na Formação Rio Bonito na área de Pântano Grande (Folha de Quitëria) ricas associações de fragmen tcs de plantas, dominadas em alguns niveis por articuladas arbusti vas designadas como Phyllotheca indica.

Úm detalhámento no estudo das caracteristicas das articuladas, na associação, levou a identificação do tipo de estrutuas reprodutivas destes fragmentos.

os fragmentos de caules que ocorrem dispersos em alguns niveis (largura 10 a $45 \mathrm{~mm}$ ) apresentam carenas e sulcos longitudinais paralelos e que não sofrem alternância de posição na linha nodal (Est. 1, fig. 4). Dos nós partem, em alguns fragmentos, ramificações laterais, sugerindo que estes representariam o caule de. forma arbustivas (Est. 1, fig. 5). Estes fragmentos tem sido designados, em sedimentos gonduânicos como Paracalamites; essa designação, con forme BOUREAU (1971), não é correta, pois caracteriza originalmente, plantas arborescentes relacionadas a Calamostachyales (Carboni fero inferior - Província Euroamericana).

Em outros fragmentos de ramos muito finos (diâmetro $4 \mathrm{~mm}$ ) par tem verticilios de folhas fusionadas na base, formando uma bainha cônica, que recobre quase todo o internódio. As partes livres das folhas apresentam variação de tamanho em diferentes verticỉlios (5 a $12 \mathrm{~mm}$ ) (Est. 1, fig. 3).

Em um nível muito próximo à camada de carvão, ocorrem fragmen tos nas quais a estrutura do aparelho reprodutivo é evidenciada. Nos ramos fērteis não é observada a costelação dos caules. Isto ocorre porque as bainhas foliares muito amplas recobrem quase totalmente a superfície dos ramos. Conjuntos de esporangióforos são observados associados, de forma ramificada, junto à parte inferior dos internódios. Não se observa, todavia, o tipo de inserção do ei xo portador dos esporangióforos, embora em alguns níveis seja observada a presença de um eixo único, que se ramificaria após. A parte vegetativa, nestes ramos, é relacionada ao gênero Phyllotheca (Est. 2, fig. 1). Este tipo de estruturação do aparelho reprodu tor permite uma associação com a familia Gondwanostachyaceae (MEYEN, 1967) restrita a sedimentos gonduânicos. 
Por restarem dúvidas quanto a forma de inserção do aparelho reprodutor nos ramos, ainda não foi efetuada uma determinação a ni vel genérico, a qual será efetuada ao final do presente estudo.

GUERRA-SOMMER (1989) relaciona a ocorrência de Botrychiopsis plantiana e Phyllotheca, em ambientes higröfilos, nos níveis basais da Formação Rio Bonito, a um clima frio. Já nas tafocenoses associadas a camadas de carvão, os ambientes higrófilos são domina dos por Phyllotheca, na ausência de Botrychiopsis. Esta evidência está relacionada a amenização do clima, que passaria a ser tempera do.

Comparando-se os registros de articuladas no Gondwana Sul-rio -grandense com aqueles efetuados na porção mais setentrional da Ba cia do Paraná, observa-se que (Estados de são Paulo e Paraná) apenas o gênero Sphenophyllum (Bowmanitales Cq. Meyen, 1987), ocorre como representante comum. Até o presente não há registros de formas relacionadas a Phyllotheca ou Gondwanostachys. Por outro lado, na parte sul da Bacia, o gênero Sphenophyllum não tem sito registrado nas associações. Estes dados poderiam indicar, talvez, a pre sença de "barreiras" que impedissem a presença associada destas for mas (Sphenophyllum e Phyllotheca) nas floras do Permiano da Bacia do Paraná.

\section{BIBLIOGRAFIA}

ARBER, E.A.N. 1905. Catalogue of the Fossil Plants of Glossopteris Flora. Department of Geology, British Museum (Natural History). London. $255 \mathrm{p}$.

BARBOSA, O. 1958. On the Age of the Lower Gondwana Floras in Brazil and Abroad. In: INTERNACIONAL GEOLOGICAL CONGRESS, 20, Mexico, Annals... p. 206-36.

BOUKEAU, E. 1971. Les Sphenophytes Biologie et Historie Evolutive. Paris, Librairie Vuibert. $167 \mathrm{p}$.

BURJACK, M.I. et al. 1983. Perfil Paleoecológico do Afloramento Mor ro Papaléo, Permiano Inferior da Bacia do Paraná,RS,Brasil. In: CONGRESSO BRASILEIRO DE GEOLOGIA, 32, Anais... Salvador, V.4, p. $1260-70$.

CAZZULO-KLEPZIG, M. \& GUERRA-SOMMER, M. 1983a. O morfogênero Phyllọ theca em sedimentos da Formação Rio Bonito no Rio Grande do Sul. In: SIMPÓSIO SUL-BRASILEIRO DE GEOLOGIA, 1, Porto Alegre, Anais... Porto Alegre, Sociedade Brasileira de Geologia, p.160-9.

GUERRA-SOMMER, M. 1989. Megafloras ocorrentes em horizontes associa dos a carvão no Rio Grande do Sul. In: SIMPOSIo SUL-BRASILEIRO DE GEOLOGIA, 4, Porto Alegre, Atas. (no prelo) 
HARTT, C.F. 1870. In Agassiz, Scientific Results of a Journey in Brazil. Geology and Physical Geography of Brazil. Boston and Lon don.

HIRMER, M. 1927. Handbuch der Paleobotanik, XVI + 780p. text-fig. Nürenberg.

LIAIS, E. 1972, Climats, Géologie, Faune et Geograhie Bontanic du Brésil. Paris, Carnier, $640 \mathrm{p}$.

LUNDQUIST, G. 1919. Fossile Pflanzen der Glossopteris Flora aus Brasilien. Kurgliga Svenska Vetenskapsakademiens Handlingar, Uppsala, $60(3): 1-36$.

MEYEN, S.V. 1967. New data on Relationship Between Angara Flora and Gondwana Late Paleozoic Floras. In: IUGS SYNPOSIUM, Buenos Aires, p. 144-52.

1987. Fundamentals of PaZaeobotany, London, Chapman and Hall. $432 \mathrm{p}$.

TOWNROW, J.A. 1955. On Some species of Phyllotheca. J.and Proc.Roy. Soc. New South Wales. Vol. 89, pt. 1, p. 39-63.

\title{
LEGENDA
}

\author{
ESTAMPA I \\ Phyleotheca indica \\ Fig. 1 - Bainha onde se evidenciam os sulcos \\ pela fusão foliar (X 5,5) \\ 2 - Verticilio foliar; folhas lineares \\ fusionadas na base. (X 7) \\ 3 - Secção longitudinal do ramo com bainhas \\ foliares claramente evidenciadas. (x 2,5) \\ 4 - Detalhe da região do nó. (x 4) \\ 5 - Eixo com ramificação ao nível dos nós. \\ Verticilio foliar isolado no topo esquerdo (x 1) \\ ESTAMPA II \\ Gondwanostachiaceae? \\ Fig. 1 - Fragmento fértil com conjunto de esporangiófo- \\ ros na região interior de cada internódio. \\ Folhas do tipo Phyllotheca. (x 11)
}



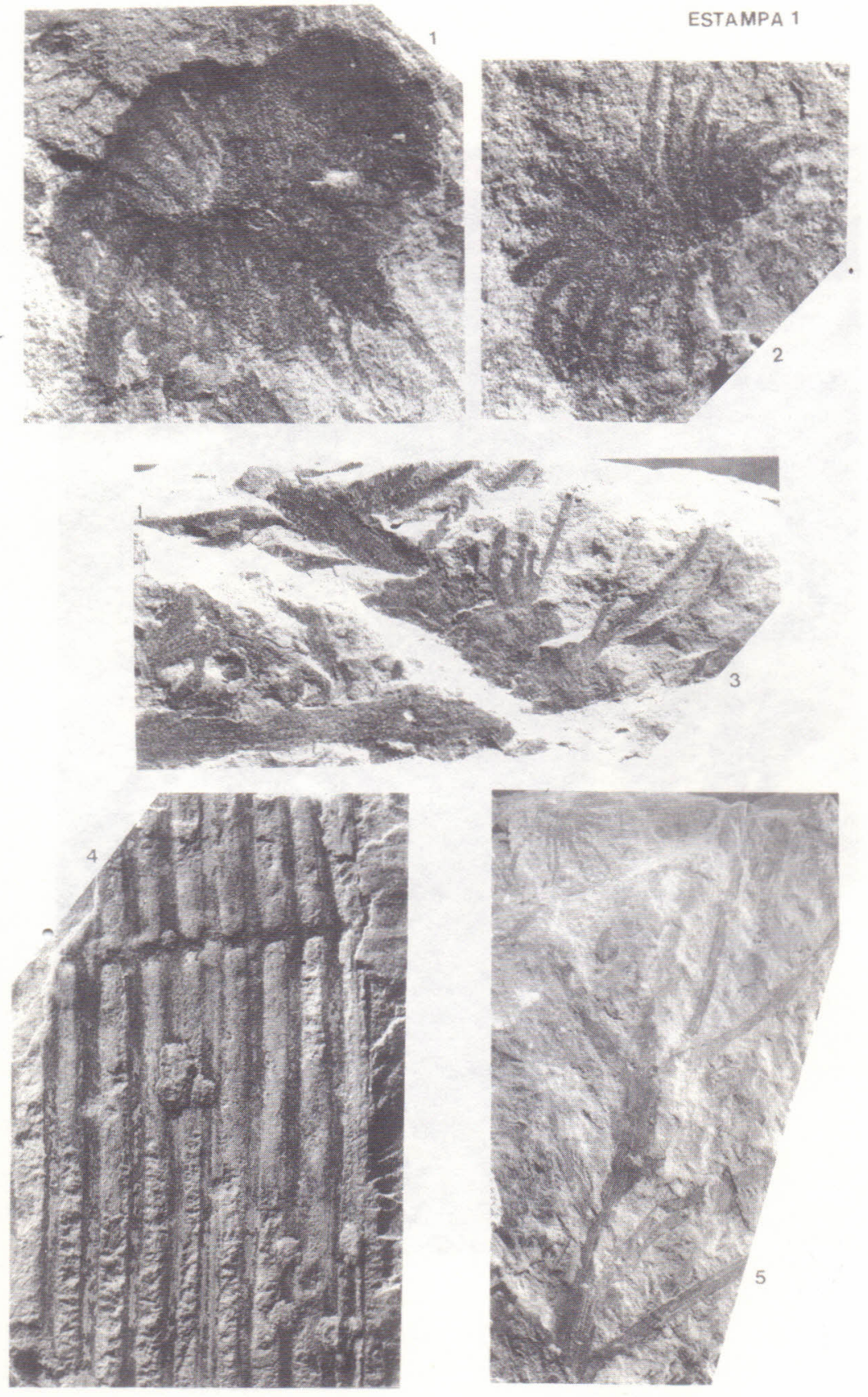


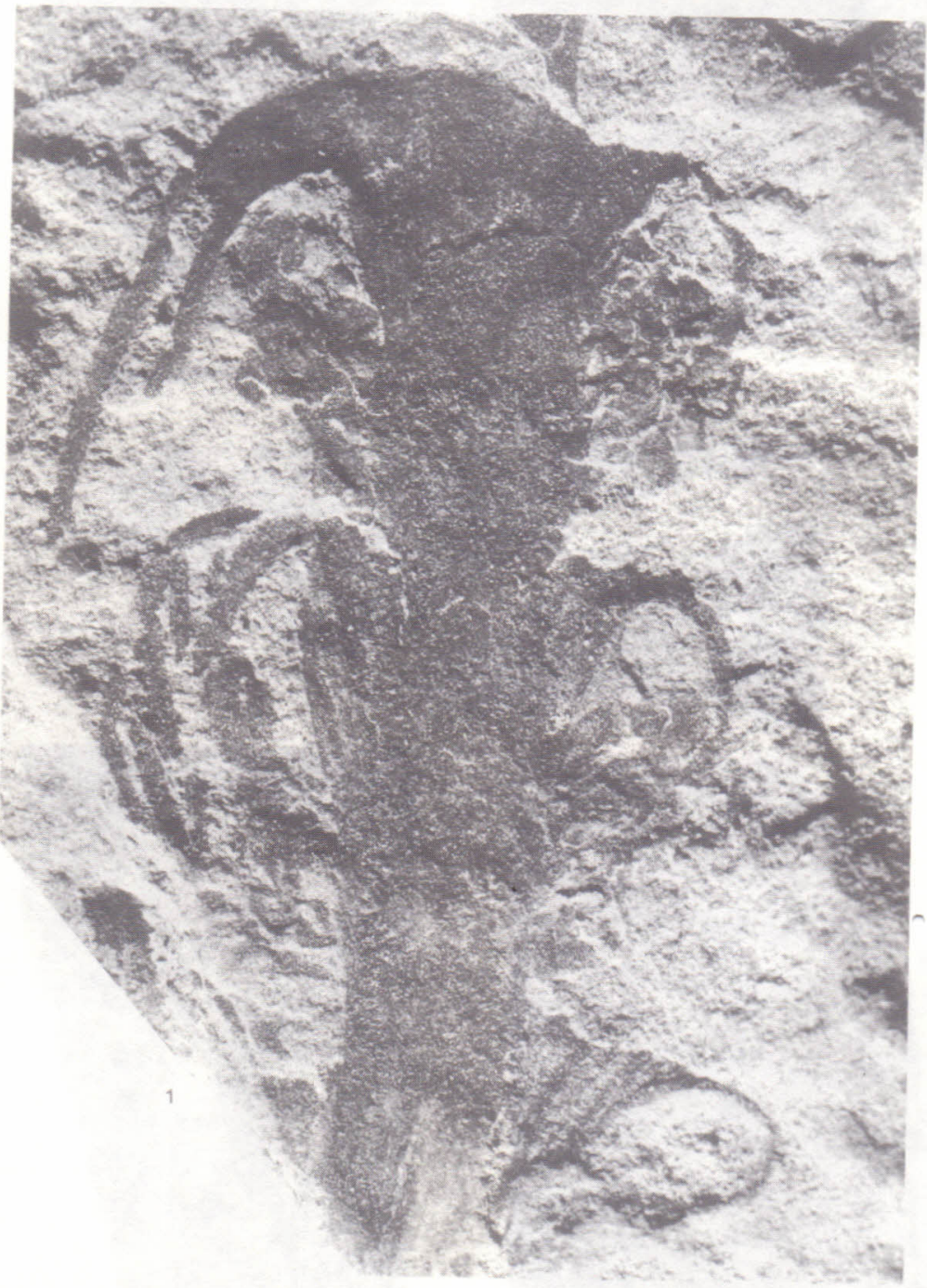

